\title{
KOMUNIKASI INTERPERSONAL KEPEMIMPINAN KEPALA SEKOLAH DAN BUDAYA KERJA ORGANISASI TERHADAP MOTIVASI KERJA DAN DAMPAKNYA PADA KEPUASAN KERJA GURU SEKOLAH MENENGAH PERTAMA
}

\author{
Sri Rahayu \\ SMP Negeri 4 Wonogiri \\ srirahayu.1234@yahoo.com
}

\begin{abstract}
Interest empirically, examine (1) the contribution of interpersonal communication, school leadership, and culture of the organization's work on job satisfaction indirectly through work motivation of teachers, (2) the contribution of interpersonal communication, school leadership, and culture of the organization's work on work motivation, and (3) the contribution of work motivation on job satisfaction of teachers. Type quantitative correlation. Sampling using simple random sampling technique. The research sample as many as 182 teachers. Collecting data using questionnaires. Data analysis techniques with path analysis. The results of the study, 1) interpersonal communication, school leadership and work culture of the organization have simultaneous and significant contribution to job satisfaction indirectly through job motivation of teachers; 2) interpersonal communication, school leadership and work culture of the organization to contribute directly to the work motivation; and 3) Motivation to contribute directly to job satisfaction of teachers.
\end{abstract}

Keywords: interpersonal communication, school leadership, organizational work culture, work motivation, job satisfaction of teachers

\begin{abstract}
ABSTRAK
Tujuan penelitia, menguji (1) kontribusi komunikasi interpersonal, kepemimpinan kepala sekolah, dan budaya kerja organisasi terhadap kepuasan kerja secara tidak langsung melalui motivasi kerja guru, (2) kontribusi komunikasi interpersonal, kepemimpinan kepala sekolah, dan budaya kerja organisasi terhadap motivasi kerja, dan (3) kontribusi motivasi kerja terhadap kepuasan kerja guru. Jenis penelitian kuantitatif korelasional. Pengambilan sampel menggunakan teknik simple random sampling. Sampel penelitian sebanyak 182 guru. Pengumpulan data menggunakan metode angket. Teknik analisis data dengan analisis jalur. Hasil penelitian, 1) Komunikasi interpersonal, kepemimpinan kepala sekolah dan budaya kerja organisasi mempunyai kontribusi secara simultan dan signifikan terhadap kepuasan kerja secara tidak langsung melalui motivasi kerja guru; 2) Komunikasi interpersonal, kepemimpinan kepala sekolah dan budaya kerja organisasi berkontribusi secara langsung terhadap motivasi kerja; dan 3) Motivasi kerja berkontribusi secara langsung terhadap kepuasan kerja guru.
\end{abstract}


Kata kunci : komunikasi interpersonal, kepemimpinan kepala sekolah, budaya kerja organisasi, motivasi kerja, kepuasan kerja guru

\section{PENDAHULUAN}

Pengembangan sumber daya manusia merupakan pengaruh sangat penting bagi kesuksesan dan kesinambungan pembangunan oleh karena itu pembangunan dan peningkatan kualitas sumber daya manusia mutlak diperlukan. Dalam konteks pembangunan sumber daya manusia pendidikan pada dasarnya merupakan proses mencerdaskan kehidupan bangsa dan pengembangan manusia Indonesia seutuhnya (Nuchiyah, 2007:1).

Kepemimpinan merupakan proses mempengaruhi orang lain untuk mengambil langkahlangkah atau tindakan menuju suatu sasaran bersama. Karena itu kepemimpinan adalah kegiatan mempengaruhi orang lain agar mau bekerja untuk mencapai tujuan yang telah ditentukan (Purwanti, 2013:212).

Organisasi adalah suatu kelompok orang dalam sebuah wadah atau perkumpulan untuk tujuan bersama. Kelompok tersebut terdiri dari orang-orang yang saling berinteraksi, berkomunikasi, berkiprah dengan perbedaan latar belakang, perbedaaan pengalaman pribadi, dan perbedaaan sosial. Sebagai makhluk sosial inilah manusia melakukan interaksi satu sama lain, tolong-menolong, pengaruh-mempengaruhi, bekerja sama untuk mencapai tujuan yang sama. Interaksi merupakan syarat utama terjadinya aktivitas sosial, dimana menunjukkan hubungan sosial antara sesama manusia atau orang perorang, antara kelompok manusia maupun antara orang perorang dengan kelompok manusia. Ukuran organisasi merupakan faktor utama yang mempengaruhi keselamatan kinerja. Konstruksi organisasi yang lebih besar memiliki kedudukan yang lebih baik daripada yang lebih kecil karena mereka memiliki sumber daya yang lebih besar. (Sunindijo, 2015:110)

Unsur motivasi kerja terbagi menjadi tiga bagian yaitu arah perilaku, tingkat usaha dan tingkat kegigihan. Dalam bekerja arah perilaku (direction of behavior) mengacu pada perilaku yang dipilih seseorang dalam bekerja dari banyak pilihan perilaku yang dapat mereka jalankan, baik tepat maupun tidak. Tingkat usaha berbicara mengenai seberapa keras usaha seseorang untuk bekerja sesuai dengan perilaku yang dipilih. (George dalam Adiwinata, 2014:2). Motivasi adalah kesediaan untuk mengeluarkan tingkat upaya yang tinggi ke arah tujuan organisasi, yang dikondisikan oleh kemampuan upaya itu untuk memenuhi suatu kebutuhan individual. Motivasi kerja dapat didefinisikan sebagai "suatu dorongan secara psikologis kepada seseorang yang menentukan arah dari perilaku (direction of behavior) seseorang dalam organisasi, tingkat usaha (level of effort), dan tingkat kegigihan atau ketahanan di dalam menghadapi suatu halangan atau masalah (level of persistence)" (Robbins dalam Adiwinata, 2014:2)

Kepuasan kerja, motivasi kerja dan komitmen normatif guru sangat berperan untuk meningkatkan kinerja guru bila secara bersama-sama. Guru yang memiliki kepuasan kerja yang tinggi dan mempunyai motivasi yang tinggi dalam bekerja serta didukung dengan komitmen normatif yang tinggi pula, tentu akan lebih maksimal dalam bekerja dan menunjukkan kinerja yang baik dibandingkan dengan guru yang kurang terpuaskan dan tidak termotivasi dalam bekerja serta tidak memiliki komitmen normatif yang tinggi. (Bestiana, 2012:198) 
Penelitian ini memfokuskan pada organisasi pendidikan yaitu sekolah-sekolah yang tergabung pada Kecamatan Wonogiri. Sekolah-sekolah yang ada di Kecamatan Wonogiri termasuk sekolah yang berada di daerah pedesaan yang jauh dari kota, namun prestasi akademis dan non-akademis dari sekolah-sekolah di Kecamatan Wonogiri cukup dirasa memiliki prestasi yang baik. Hal itu tak lepas dari peran serta para tenaga pengajarnya yaitu guru dan kepala sekolah dalam membangun prestasi anak didiknya. Dengan adanya penelitian ini diharapkan mampu menambah wawasan bagi para kepala sekolah dalam kepemimpinannya di sekolah. Seorang kepala sekolah harus mampu berkomunikasi dan memberikan motivasi kepada para guru di dalam sebuah organisasi sekolahnya, karena jika tidak adanya komunikasi yang baik dan dukungan dari atasan akan berpengaruh kepada prestasi kerja bawahannya. Komunikasi yang baik antara pimpinan dengan bawahan dapat membuat hubungan menjadi harmonis dan tercipta motivasi, sehingga secara otomatis bisa meningkatkan prestasi kerja atau kinerja guru.

Tujuan dalam penelitian ini adalah : 1) Untuk menganalisis dan menguji pengaruh komunikasi interpersonal terhadap motivasi kerja; 2) Untuk menganalisis dan menguji pengaruh kepemimpinan kepala sekolah terhadap motivasi kerja; 3) Untuk menganalisis dan menguji pengaruh budaya kerja organisasi terhadap motivasi kerja; 4) Untuk menganalisis dan menguji pengaruh komunikasi interpersonal terhadap kepuasan kerja guru; 5) Untuk menganalisis dan menguji pengaruh kepemimpinan kepala sekolah terhadap kepuasan kerja guru; 6) Untuk menganalisis dan menguji pengaruh budaya kerja organisasi terhadap kepuasan kerja guru; 7) Untuk menganalisis dan menguji pengaruh motivasi kerja terhadap kepuasan kerja guru; 8) Untuk menganalisis dan menguji pengaruh komunikasi interpersonal dan kepemimpinan kepala sekolah terhadap motivasi kerja; 9) Untuk menganalisis dan menguji pengaruh kepemimpinan kepala sekolah dan budaya kerja organisasi terhadap motivasi kerja; 10) Untuk menganalisis dan menguji pengaruh komunikasi interpersonal dan budaya kerja organisasi terhadap motivasi kerja; 11) Untuk menganalisis dan menguji pengaruh komunikasi interpersonal, kepemimpinan kepala sekolah dan budaya kerja organisasi terhadap motivasi kerja; 12) Untuk menganalisis dan menguji pengaruh komunikasi interpersonal dan kepemimpinan kepala sekolah terhadap kepuasan kerja guru; 13) Untuk menganalisis dan menguji pengaruh kepemimpinan kepala sekolah dan budaya kerja organisasi terhadap kepuasan kerja guru; 14) Apakah komunikasi interpersonal dan budaya kerja organisasi terhadap kepuasan kerja guru; 15) Untuk menganalisis dan menguji pengaruh komunikasi interpersonal, kepemimpinan kepala sekolah dan budaya kerja organisasi terhadap kepuasan kerja guru; 16) Untuk menganalisis dan menguji pengaruh komunikasi interpersonal, kepemimpinan kepala sekolah dan budaya kerja organisasi terhadap motivasi kerja; 17) Untuk menganalisis dan menguji pengaruh komunikasi interpersonal, kepemimpinan kepala sekolah dan budaya kerja organisasi terhadap kepuasan kerja guru.

\section{METODE}

Penelitian ini merupakan jenis penelitian korelasional dengan menggunakan pendekatan kuantitatif. Penelitian bertempat di SMP Kecamatan Wonogiri yakni SMP N 1 Wonogiri, SMP N 2 Wonogiri, SMP N 3 Wonogiri, SMP N 4 Wonogiri, SMP N 5 Wonogiri, SMP N 6 Wonogir, dan SMP N 7 Wonogiri. Penelitian dilaksanakan pada semester genap tahun 
ajaran 2015/2016 yaitu pada bulan Januari 2016 sampai dengan bulan Juni 2016. Populasi yang dipergunakan dalam penelitian ini adalah 334 guru dengan sampel yang dipakai adalah sebanyak 182 guru. Dalam pengambilan sampel penulis menggunakan teknik simple random sampling dan dalam pengumpulan data peneliti menggunakan metode angket. Teknik analisis data dengan analisis jalur.

\section{HASIL DAN PEMBAHASAN}

Hasil uji validitas instrumen variabel komunikasi interpersonal mempunyai $r_{\text {hitung }}$ yang lebih besar dari $r_{\text {tabel }}$ yaitu 0,148 , serta hasil taraf signifikansi yang kurang dari 0,05 . Hal ini berarti indikator-indikator yang digunakan dalam variabel komunikasi interpersonal layak atau valid digunakan sebagai pengumpul data. Hasil uji validitas instrumen variabel kepemimpinan kepala sekolah mempunyai $r_{\text {hitung }}$ yang lebih besar dari $r_{\text {tabel }}$ yaitu 0,148 , serta hasil taraf signifikansi yang kurang dari 0,05 . Hal ini berarti indikator-indikator yang digunakan dalam variabel kepemimpinan kepala sekolah layak atau valid digunakan sebagai pengumpul data. Hasil uji validitas instrumen variabel budaya kerja organisasi mempunyai $r_{\text {hitung }}$ yang lebih besar dari $r_{\text {tabel }}$ yaitu 0,148 , serta hasil taraf signifikansi yang kurang dari 0,05. Hal ini berarti indikator-indikator yang digunakan dalam variabel budaya kerja organisasi layak atau valid digunakan sebagai pengumpul data. Hasil uji validitas instrumen variabel motivasi kerja mempunyai $r_{\text {hitung }}$ yang lebih besar dari $r_{\text {tabel }}$ yaitu 0,148 , serta hasil taraf signifikansi yang kurang dari 0,05. Hal ini berarti indikator-indikator yang digunakan dalam variabel motivasi kerja layak atau valid digunakan sebagai pengumpul data. Hasil uji validitas instrumen variabel kepuasan kerja guru mempunyai $r_{\text {hitung }}$ yang lebih besar dari $r_{\text {tabel }}$ yaitu 0,148 , serta hasil taraf signifikansi yang kurang dari 0,05 . Hal ini berarti indikatorindikator yang digunakan dalam variabel kepuasan kerja guru layak atau valid digunakan sebagai pengumpul data.

Berdasarkan hasil perhitungan uji reliabelitas diperoleh nilai Cronbach's Alpha pada masing-masing variabel disajikan pada tabel 1.

Tabel 1. Hasil Uji Reliabilitas

\begin{tabular}{cc}
\hline Variabel & Cronbach's Alpha \\
\hline Komunikasi interpersonal $\left(\mathrm{X}_{1}\right)$ & 0,382 \\
Kepemimpinan kepala sekolah $\left(\mathrm{X}_{2}\right)$ & 0,442 \\
Budaya kerja organisasi $\left(\mathrm{X}_{3}\right)$ & 0,545 \\
Motivasi kerja $(\mathrm{Y})$ & 0,555 \\
\hline Kepuasan kerja guru $(\mathrm{Z})$ & 0,447 \\
\hline
\end{tabular}

Sumber : Hasil olah data

Tabel 1. menunjukkan bahwa hasil analisis sesuai dengan kriteria penilaian yang telah ditentukan. Setiap variabel penelitian yang diuji, nilai cronbach's alpha yang dimiliki lebih besar dari 0,148. Hal ini berarti variabel dalam penelitian ini adalah reliabel dan dapat dipercaya keandalannya sehingga dapat digunakan kembali pada penelitian selanjutnya dengan pembahasan yang sama.

Hasil uji normalitas disajikan pada tabel 2, menunjukkan bahwa data dalam penelitian 
ini berdistribusi normal memiliki nilai $(0,257),(0,280),(0,147),(0,201),(0,202)$ yang lebih besar dari 0,05 .

Tabel 2. Hasil uji normalitas data One-Sample Kolmogorov-Smirnov Test

\begin{tabular}{ccc}
\hline Variabel & Sig & Keterangan \\
\hline Komunikasi interpersonal $\left(\mathrm{X}_{1}\right)$ & 0,257 & Sig $>0,05$ maka \\
Kepemimpinan kepala sekolah $\left(\mathrm{X}_{2}\right)$ & 0,280 & berdistribusi normal \\
Budaya kerja organisasi $\left(\mathrm{X}_{3}\right)$ & 0,147 & \\
Motivasi kerja $(\mathrm{Y})$ & 0,201 & \\
Kepuasan kerja guru $(\mathrm{Z})$ & 0,202 & \\
\hline
\end{tabular}

Sumber : Hasil olah data

Hasil uji linieritas disajikan pada tabel 3, dapat diketahui bahwa nilai signifikansi semua lebih besar dari 0,05 (sig $>0,05)$ maka hal ini menunjukkan bahwa hubungan variabel independent terhadap variabel dependent adalah linier.

Tabel 3. Hasil uji linieritas

\begin{tabular}{ccc}
\hline Variabel & Sig. & Keterangan \\
\hline Komunikasi interpersonal $\left(\mathrm{X}_{1}\right)->$ Kepuasan kerja guru $(\mathrm{Z})$ & 0,881 & Linier \\
Kepemimpinan kepala sekolah $\left(\mathrm{X}_{2}\right)->$ Kepuasan kerja guru $(\mathrm{Z})$ & 0,200 & Linier \\
Budaya kerja organisasi $\left(\mathrm{X}_{3}\right)->$ Kepuasan kerja guru $(\mathrm{Z})$ & 0,898 & Linier \\
Motivasi kerja $(\mathrm{Y})->$ Kepuasan kerja guru $(\mathrm{Z})$ & 0,916 & Linier \\
\hline
\end{tabular}

Sumber : Hasil olah data

Hasil uji multikoliniearitas disajikan pada tabel 4. Sesuai dengan ketentuan uji multikolinieritas, jika nilai VIF kurang dari 10 maka tidak terdapat korelasi. Sehingga dapat disimpulkan bahwa tidak terdapat multikolinieritas dalam data penelitian ini. Artinya bahwa semua variabel indepent tidak terjadi multikolinieritas atau tidak saling mengganggu atau saling mempengaruhi.

Tabel 4. Uji multikolinieritas

\begin{tabular}{ccc}
\hline Variabel Independent & VIF & Keterangan \\
\hline Komunikasi interpersonal $\left(\mathrm{X}_{1}\right)$ & 1,137 & Tidak terjadi multikolinieritas \\
Kepemimpinan kepala sekolah $\left(\mathrm{X}_{2}\right)$ & 1,167 & Tidak terjadi multikolinieritas \\
Budaya kerja organisasi $\left(\mathrm{X}_{3}\right)$ & 1,145 & Tidak terjadi multikolinieritas \\
Motivasi kerja $(\mathrm{Y})$ & 1,163 & Tidak terjadi multikolinieritas \\
\hline
\end{tabular}

Sumber : Hasil olah data

Hasil uji heteroskesdastisitas disajikan pada gambar 1. Dasar analisa uji heteroskodesitas dengan grafik plot adalah jika titik dalam grafik tersebar (tidak membentuk pola) maka tidak terjadi heteroskodesitas. Berdasarkan gambar tersebut dapat dilihat bahwa titik-titik yang ada tidak membentuk pola yang teratur. Sehingga dapat disimpulkan bahwa pada data dalam penelitian ini tidak terjadi heteroskodesitas. Artinya dalam fungsi regresi di penelitian ini tidak muncul gangguan karena varian yang tidak sama. 


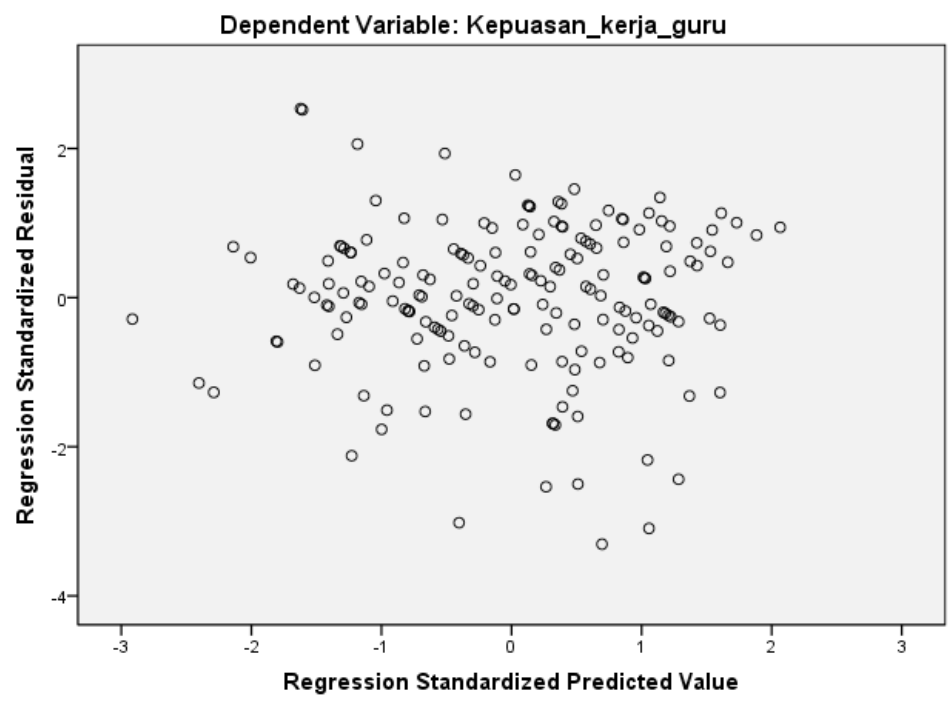

Gambar 1. Uji heteroskodesitas

Sumber : Hasil olah data

Hasil pengujian uji autokorelasi sajikan pada tabel 5, dapat diketahui nilai Durbin watson sebesar 1,474. Sehingga nilai DW berada diantara dW $(1,474)<\mathrm{dL}(1,633)$. Maka dapat disimpulkan bahwa dalam penelitian ini ada autokorelasi positif $(+)$.

Tabel 5. Uji autokorelasi

Model Summary

\begin{tabular}{|l|c|c|c|c|c|}
\hline Model & R & R Square & $\begin{array}{c}\text { Adjusted R } \\
\text { Square }\end{array}$ & $\begin{array}{c}\text { Std. Error of } \\
\text { the Estimate }\end{array}$ & $\begin{array}{c}\text { Durbin- } \\
\text { Watson }\end{array}$ \\
\hline 1 & $.740^{\mathrm{a}}$ & .547 & .537 & 3.311 & 1.474 \\
\hline
\end{tabular}

Hasil pengujian hipotesis secara simultan adalah sebagai berikut. Berdasarkan output tersebut dapat diketahui bahwa nilai $\mathrm{F}_{\text {hitung }}$ sebesar 53,493. Adapun nilai $\mathrm{F}_{\text {tabel }}$ pada tingkat signifikansi 5\% dan degree of freedom $(\mathrm{df})$ sebesar $\mathrm{k}=5$. Untuk mencari nilai df1 $(\mathrm{N} 1)=\mathrm{k}-1$ $=5-1=4$ dan untuk mencari nilai df $2(\mathrm{~N} 2)=\mathrm{n}-\mathrm{k}=182-5=177$ sehingga jika dilihat pada $\mathrm{F}_{\text {tabel }}$ adalah sebesar 2,420. Jika kedua nilai ini dibandingkan maka nilai $\mathrm{F}_{\text {hitung }}$ lebih besar dari $\mathrm{F}_{\text {tabel }}(53,493>2,420)$. Dengan hasil perbandingan 53,493>2,420 $\left(\mathrm{F}_{\text {hitung }}>\mathrm{F}_{\text {tabel }}\right)$ sehingga dengan demikian dapat disimpulkan bahwa secara simultan variabel independent (Komunikasi interpersonal, Kepemimpinan kepala sekolah, budaya kerja organisasi, dan motivasi kerja) memiliki pengaruh yang signifikan terhadap variabel dependent (kepuasan kerja guru).

\begin{tabular}{|c|c|c|c|c|c|c|}
\hline \multicolumn{7}{|c|}{ ANOVA $^{\mathrm{b}}$} \\
\hline & & $\begin{array}{c}\text { Sum of } \\
\text { Squares }\end{array}$ & df & Mean Square & $\mathrm{F}$ & Sig. \\
\hline \multirow[t]{3}{*}{1} & Regression & 2345.086 & 4 & 586.271 & 53.493 & $.000^{a}$ \\
\hline & Residual & 1939.865 & 177 & 10.960 & & \\
\hline & Total & 4284.951 & 181 & & & \\
\hline
\end{tabular}


Hasil analisis pengaruh komunikasi interpersonal terhadap motivasi kerja, diperoleh hasil perhitungan $t_{\text {hitung }}$ sebesar 4,413 yang berarti lebih besar dari $t_{\text {tabel }}=1,653$, kemudian perhitungan dari nilai signifikansi $=0,000$, yang berarti lebih kecil dari $\alpha=0,05$. Hal tersebut menunjukkan bahwa $\mathrm{H}_{0}$ ditolak dan $\mathrm{H}_{\mathrm{a}}$ diterima, sehingga komunikasi interpersonal $\left(\mathrm{X}_{1}\right)$ mempunyai pengaruh yang signifikan terhadap motivasi kerja (Y).

Hasil analisis pengaruh kepemimpinan kepala sekolah $\left(\mathrm{X}_{2}\right)$ terhadap motivasi kerja $(\mathrm{Y})$, diperoleh hasil perhitungan $\mathrm{t}_{\text {hitung }}$ sebesar $-2,270$ yang berarti lebih kecil dari $\mathrm{t}_{\text {tabel }}=1,653$, kemudian perhitungan dari nilai signifikansi $=0,024$ yang berarti lebih besar dari $\alpha=0,05$. Hal tersebut menunjukkan bahwa $\mathrm{H}_{0}$ diterima dan $\mathrm{H}_{\mathrm{a}}$ ditolak, sehingga kepemimpinan kepala sekolah $\left(\mathrm{X}_{2}\right)$ tidak mempunyai pengaruh yang signifikan terhadap motivasi kerja $(\mathrm{Y})$.

Hasil analisis pengaruh budaya kerja organisasi terhadap Motivasi kerja, diperoleh hasil perhitungan $t_{\text {hitung }}$ sebesar $-1,321$ yang berarti lebih kecil dari $t_{\text {tabel }}=1,653$, kemudian perhitungan dari nilai signifikansi $=0,188$, yang berarti lebih besar dari $\alpha=0,05$. Hal tersebut menunjukkan bahwa $\mathrm{H}_{0}$ diterima dan $\mathrm{H}_{\mathrm{a}}$ ditolak, sehingga budaya kerja organisasi $\left(\mathrm{X}_{3}\right)$ tidak mempunyai pengaruh yang signifikan terhadap motivasi kerja (Y).

Hasil analisis pengaruh Komunikasi interpersonal terhadap komunikasi interpersonal, diperoleh hasil perhitungan $\mathrm{t}_{\text {hitung }}$ sebesar 0,506 yang berarti lebih kecil dari $\mathrm{t}_{\text {tabel }}=1,653$, kemudian perhitungan dari nilai signifikansi $=0,614$, yang berarti lebih besar dari $\alpha=0,05$. Hal tersebut menunjukkan bahwa $\mathrm{H}_{0}$ diterima dan $\mathrm{H}_{\mathrm{a}}$ ditolak, sehingga Komunikasi interpersonal $\left(\mathrm{X}_{1}\right)$ tidak mempunyai pengaruh yang signifikan terhadap kepuasan kerja guru $(\mathrm{Z})$.

Hasil analisis pengaruh kepemimpinan kepala sekolah terhadap komunikasi interpersonal, diperoleh hasil perhitungan $\mathrm{t}_{\text {hitung }}$ sebesar 3,196 yang berarti lebih besar dari $\mathrm{t}_{\text {tabel }}=1,653$, kemudian perhitungan dari nilai signifikansi $=0,002$, yang berarti lebih kecil dari $\alpha=0,01$. Hal tersebut menunjukkan bahwa $\mathrm{H}_{0}$ ditolak dan $\mathrm{H}_{\mathrm{a}}$ diterima, sehingga Kepemimpinan kepala sekolah $\left(\mathrm{X}_{2}\right)$ mempunyai pengaruh yang signifikan terhadap kepuasan kerja guru $(\mathrm{Z})$.

Hasil analisis pengaruh budaya kerja organisasi terhadap komunikasi interpersonal, diperoleh hasil perhitungan $t_{\text {hitung }}$ sebesar 14,601 yang berarti lebih besar dari $t_{\text {tabel }}=1,653$, kemudian perhitungan dari nilai signifikansi $=0,000$, yang berarti lebih kecil dari $\alpha=0,05$. Hal tersebut menunjukkan bahwa $\mathrm{H}_{0}$ ditolak dan $\mathrm{H}_{\mathrm{a}}$ diterima, sehingga budaya kerja organisasi $\left(\mathrm{X}_{3}\right)$ mempunyai pengaruh yang signifikan terhadap kepuasan kerja guru $(\mathrm{Z})$.

Hasil analisis pengaruh motivasi kerja $(Y)$ terhadap kepuasan kerja guru $(\mathrm{Z})$, diperoleh hasil perhitungan $t_{\text {hitung }}$ sebesar $-1,980$ yang berarti lebih besar dari $t_{\text {tabel }}=1,653$, kemudian perhitungan dari nilai signifikansi $=0,049$, yang berarti lebih kecil dari $\alpha=0,05$. Hal tersebut menunjukkan bahwa $\mathrm{H}_{0}$ ditolak dan $\mathrm{H}_{\mathrm{a}}$ diterima, sehingga Motivasi kerja (Y) mempunyai pengaruh yang signifikan terhadap kepuasan kerja guru (Z).

Hasil analisis Komunikasi interpersonal $\left(\mathrm{X}_{1}\right)$ dan Kepemimpinan kepala sekolah $\left(\mathrm{X}_{2}\right)$ terhadap Motivasi kerja (Y), diperoleh hasil perhitungan $\mathrm{F}_{\text {hitung }}$ sebesar 13,879 yang berarti lebih besar dari $\mathrm{F}_{\text {tabel }}$ sebesar 2,420, sehingga $\mathrm{F}_{\text {hitung }}>\mathrm{F}_{\text {tabel }}$ atau $(13,879>2,420)$, kemudian perhitungan dari nilai signifikansi $=0,000$ yang berarti lebih kecil dari $\alpha=0,05$. Hal tersebut menunjukkan bahwa $\mathrm{H}_{0}$ ditolak dan $\mathrm{H}_{\mathrm{a}}$ diterima, sehingga komunikasi interpersonal $\left(\mathrm{X}_{1}\right)$ dan kepemimpinan kepala sekolah $\left(\mathrm{X}_{2}\right)$ mempunyai pengaruh secara simultan dan signifikan terhadap motivasi kerja (Y).

Hasil analisis Kepemimpinan kepala sekolah $\left(\mathrm{X}_{2}\right)$ dan budaya kerja organisasi $\left(\mathrm{X}_{3}\right)$ 
terhadap Motivasi kerja (Y), diperoleh hasil perhitungan $\mathrm{F}_{\text {hitung }}$ sebesar 2,882 yang berarti lebih besar dari $F_{\text {tabel }}$ sebesar 2,420, sehingga $F_{\text {hitung }}>F_{\text {tabel }}$ atau $(2,882>2,420)$, kemudian perhitungan dari nilai signifikansi $=0,059$ yang berarti lebih besar dari $\alpha=0,05$. Hal tersebut menunjukkan bahwa $\mathrm{H}_{0}$ diterima dan $\mathrm{H}_{\mathrm{a}}$ ditolak, sehingga Kepemimpinan kepala sekolah $\left(\mathrm{X}_{2}\right)$ dan budaya kerja organisasi $\left(\mathrm{X}_{3}\right)$ tidak mempunyai pengaruh secara simultan dan signifikan terhadap Motivasi kerja (Y).

Hasil analisis komunikasi interpersonal $\left(\mathrm{X}_{1}\right)$ dan budaya kerja organisasi $\left(\mathrm{X}_{3}\right)$ terhadap motivasi kerja (Y), diperoleh hasil perhitungan $\mathrm{F}_{\text {hitung }}$ sebesar 11,807 yang berarti lebih besar dari $\mathrm{F}_{\text {tabel }}$ sebesar 2,420, sehingga $\mathrm{F}_{\text {hitung }}>\mathrm{F}_{\text {tabel }}$ atau $(11,807>2,420)$, kemudian perhitungan dari nilai signifikansi $=0,000$ yang berarti lebih kecil dari $\alpha=0,05$. Hal tersebut menunjukkan bahwa $\mathrm{H}_{0}$ ditolak dan $\mathrm{H}_{\mathrm{a}}$ diterima, sehingga komunikasi interpersonal $\left(\mathrm{X}_{1}\right)$ dan budaya kerja organisasi $\left(\mathrm{X}_{3}\right)$ mempunyai pengaruh secara simultan dan signifikan terhadap motivasi kerja (Y).

Hasil analisis Komunikasi interpersonal $\left(\mathrm{X}_{1}\right)$, Kepemimpinan kepala sekolah $\left(\mathrm{X}_{2}\right)$ dan budaya kerja organisasi $\left(\mathrm{X}_{3}\right)$ terhadap Motivasi kerja $(\mathrm{Y})$, diperoleh hasil perhitungan $\mathrm{F}_{\text {hitung }}$ sebesar 9,677 yang berarti lebih besar dari $F_{\text {tabel }}$ sebesar 2,420, sehingga $F_{\text {hitung }}>F_{\text {tabel }}$ atau $(9,677>2,420)$ dan nilai signifikansi $<\alpha$ atau $(0,000<0,05)$. Hal tersebut menunjukkan bahwa $\mathrm{H}_{0}$ ditolak dan $\mathrm{H}_{\mathrm{a}}$ diterima, sehingga Komunikasi interpersonal $\left(\mathrm{X}_{1}\right)$, Kepemimpinan kepala sekolah $\left(\mathrm{X}_{2}\right)$ dan budaya kerja organisasi $\left(\mathrm{X}_{3}\right)$ mempunyai pengaruh secara simultan dan signifikan terhadap Motivasi kerja (Y).

Hasil analisis komunikasi interpersonal $\left(\mathrm{X}_{1}\right)$ dan kepemimpinan kepala sekolah $\left(\mathrm{X}_{2}\right)$ terhadap kepuasan kerja guru $(\mathrm{Z})$, diperoleh hasil perhitungan $\mathrm{F}_{\text {hitung }}$ sebesar 5,118 yang berarti lebih besar dari $F_{\text {tabel }}$ sebesar 2,420, sehingga $F_{\text {hitung }}>F_{\text {tabel }}$ atau $(5,118>2,420)$, kemudian perhitungan dari nilai signifikansi $=0,007$ yang berarti lebih kecil dari $\alpha=0,05$. Hal tersebut menunjukkan bahwa $\mathrm{H}_{0}$ ditolak dan $\mathrm{H}_{\mathrm{a}}$ diterima, sehingga komunikasi interpersonal $\left(\mathrm{X}_{1}\right)$ dan kepemimpinan kepala sekolah $\left(\mathrm{X}_{2}\right)$ mempunyai pengaruh secara simultan dan signifikan terhadap kepuasan kerja guru $(\mathrm{Z})$.

Hasil analisis kepemimpinan kepala sekolah $\left(\mathrm{X}_{2}\right)$ dan budaya kerja organisasi $\left(\mathrm{X}_{3}\right)$ terhadap kepuasan kerja guru $(\mathrm{Z})$, diperoleh hasil perhitungan $\mathrm{F}_{\text {hitung }}$ sebesar 106,210 yang berarti lebih besar dari $F_{\text {tabel }}$ sebesar 2,420, sehingga $F_{\text {hitung }}>F_{\text {tabel }}$ atau $(106,210>2,420)$, kemudian perhitungan dari nilai signifikansi $=0,000$ yang berarti lebih kecil dari $\alpha=0,05$. Hal tersebut menunjukkan bahwa $\mathrm{H}_{0}$ ditolak dan $\mathrm{H}_{\mathrm{a}}$ diterima, sehingga kepemimpinan kepala sekolah $\left(\mathrm{X}_{2}\right)$ dan budaya kerja organisasi $\left(\mathrm{X}_{3}\right)$ mempunyai pengaruh secara simultan dan signifikan terhadap kepuasan kerja guru $(\mathrm{Z})$.

Hasil analisis komunikasi interpersonal $\left(\mathrm{X}_{1}\right)$ dan budaya kerja organisasi $\left(\mathrm{X}_{3}\right)$ terhadap kepuasan kerja guru $(\mathrm{Z})$, diperoleh hasil perhitungan $\mathrm{F}_{\text {hitung }}$ sebesar 106,215 yang berarti lebih besar dari $F_{\text {tabel }}$ sebesar 2,420, sehingga $F_{\text {hitung }}>F_{\text {tabel }}$ atau $(106,215>2,420)$, kemudian perhitungan dari nilai signifikansi $=0,000$ yang berarti lebih kecil dari $\alpha=0,05$. Hal tersebut menunjukkan bahwa $\mathrm{H}_{0}$ ditolak dan $\mathrm{H}_{\mathrm{a}}$ diterima, sehingga komunikasi interpersonal $\left(\mathrm{X}_{1}\right)$ dan budaya kerja organisasi $\left(\mathrm{X}_{3}\right)$ mempunyai pengaruh secara simultan dan signifikan terhadap kepuasan kerja guru (Z).

Hasil analisis komunikasi interpersonal $\left(\mathrm{X}_{1}\right)$, kepemimpinan kepala sekolah $\left(\mathrm{X}_{2}\right)$ dan budaya kerja organisasi $\left(\mathrm{X}_{3}\right)$ terhadap kepuasan kerja guru $(\mathrm{Z})$, diperoleh hasil perhitungan 
$\mathrm{F}_{\text {hitung }}$ sebesar 70,535 yang berarti lebih besar dari $\mathrm{F}_{\text {tabel }}$ sebesar 2,420, sehingga $\mathrm{F}_{\text {hitung }}>\mathrm{F}_{\text {tabel }}$ atau $(70,535>2,420)$, kemudian perhitungan dari nilai signifikansi $=0,000$ yang berarti lebih kecil dari $\alpha=0,05$. Hal tersebut menunjukkan bahwa $\mathrm{H}_{0}$ ditolak dan $\mathrm{H}_{\mathrm{a}}$ diterima, sehingga komunikasi interpersonal $\left(\mathrm{X}_{1}\right)$, kepemimpinan kepala sekolah $\left(\mathrm{X}_{2}\right)$ dan budaya kerja organisasi $\left(\mathrm{X}_{3}\right)$ mempunyai pengaruh secara simultan dan signifikan terhadap kepuasan kerja guru $(\mathrm{Z})$.

Hasil analisis komunikasi interpersonal $\left(\mathrm{X}_{1}\right)$, kepemimpinan kepala sekolah $\left(\mathrm{X}_{2}\right)$ dan budaya kerja organisasi $\left(\mathrm{X}_{3}\right)$ terhadap motivasi kerja $(\mathrm{Y})$, diperoleh hasil perhitungan $\mathrm{F}_{\text {hitung }}$ sebesar 9,677 yang berarti lebih besar dari $\mathrm{F}_{\text {tabel }}$ sebesar 2,420 , sehingga $\mathrm{F}_{\text {hitung }}>\mathrm{F}_{\text {tabel }}$ atau $(9,677$ $>2,420$ ), kemudian hasil nilai signifikansi $=0,000$ yang berarti lebih kecil dari $\alpha=0,05$. Hal tersebut menunjukkan bahwa $\mathrm{H}_{0}$ ditolak dan $\mathrm{H}_{\mathrm{a}}$ diterima, sehingga komunikasi interpersonal $\left(\mathrm{X}_{1}\right)$, kepemimpinan kepala sekolah $\left(\mathrm{X}_{2}\right)$ dan budaya kerja organisasi $\left(\mathrm{X}_{3}\right)$ berpengaruh secara langsung terhadap Motivasi kerja (Y).

Hasil analisis Komunikasi interpersonal $\left(\mathrm{X}_{1}\right)$, Kepemimpinan kepala sekolah $\left(\mathrm{X}_{2}\right)$ dan budaya kerja organisasi $\left(\mathrm{X}_{3}\right)$ terhadap kepuasan kerja guru $(\mathrm{Z})$, diperoleh hasil perhitungan dari nilai signifikansi $=0,000$ yang berarti lebih kecil dari $\alpha=0,05$. Hal tersebut menunjukkan bahwa $\mathrm{H}_{0}$ ditolak dan $\mathrm{H}_{\mathrm{a}}$ diterima, sehingga Komunikasi interpersonal $\left(\mathrm{X}_{1}\right)$, Kepemimpinan kepala sekolah $\left(\mathrm{X}_{2}\right)$ dan budaya kerja organisasi $\left(\mathrm{X}_{3}\right)$ berpengaruh secara langsung terhadap kepuasan kerja guru (Z).

Pada hipotesis pertama yakni diduga komunikasi interpersonal berpengaruh secara signifikan terhadap motivasi kerja, hasil penelitian menunjukkan bahwa komunikasi interpersonal mempunyai pengaruh positif dan signifikan terhadap motivasi kerja. Hasil penelitian tersebut linier dengan penelitian dari Duta yang menyatakan bahwa keterampilan komunikasi dan motivasi kerja memiliki pengaruh yang tinggi dalam aspek pengajaran. Gaya komunikasi guru dapat mempengaruhi motivasi dan kinerja guru dalam menciptakan suasana yang menyenangkan. (Duta, 2015:1011). Hasil penelitian serupa dari Rahardja yang menyatakan bahwa terdapat hubungan antara variabel komunikasi antarpribadi guru dan motivasi kerja guru secara bersama-sama dengan variabel kinerja guru. (Rahardja, 2004:1).

Pada hipotesis kedua yakni diduga kepemimpinan kepala sekolah berpengaruh secara signifikan terhadap motivasi kerja, hasil penelitian menunjukkan bahwa kepemimpinan kepala sekolah mempunyai pengaruh tidak signifikan terhadap motivasi kerja. Hasil penelitian tersebut tidak linier dengan penelitian dari Kamaliah, dkk yang menyatakan bahwa gaya kepemimpinan, budaya organisasi, motivasi kerja yang tepat dan efektif mampu meningkatkan kinerja akuntan dan semuanya berpengaruh secara positif dan signifikan (Kamaliah, dkk 2011:1). Hasil penelitian penulis tidak linier karena hasil penelitian penulis ini terdapat keterbatasan dalam penelitian dikarenakan instrumen dibuat sendiri oleh peneliti dan responden tidak dikendalikan.

Pada hipotesis ketiga yakni diduga budaya kerja organisasi berpengaruh secara signifikan terhadap motivasi kerja, hasil penelitian menunjukkan bahwa budaya kerja organisasi mempunyai pengaruh tidak signifikan terhadap motivasi kerja. Hasil penelitian tersebut tidak linier dengan penelitian dari Kamilin yang menyatakan bahwa budaya organisasi berpengaruh langsung terhadap motivasi kerja guru (Kamilin, 2013:78). Hasil penelitian penulis tidak linier karena hasil penelitian penulis ini terdapat keterbatasan dalam penelitian dikarenakan instrumen dibuat sendiri oleh peneliti dan responden tidak dikendalikan. 
Pada hipotesis keempat yakni diduga komunikasi interpersonal berpengaruh secara signifikan terhadap kepuasan kerja guru, hasil penelitian menunjukkan bahwa komunikasi interpersonal mempunyai pengaruh positif tetapi tidak signifikan terhadap kepuasan kerja guru. Hasil penelitian tersebut tidak linier dengan penelitian dari Cetin et al yang menyatakan bahwa gaya kepemimpinan interaktif dan komunikasi interpersonal memiliki hubungan yang kuat terhadap kepuasan kerja (Cetin et al., 2012:227). Hasil penelitian penulis tidak linier karena hasil penelitian penulis ini terdapat keterbatasan dalam penelitian dikarenakan instrumen dibuat sendiri oleh peneliti dan responden tidak dikendalikan.

Pada hipotesis kelima yakni diduga kepemimpinan kepala sekolah berpengaruh secara signifikan terhadap kepuasan kerja guru, hasil penelitian menunjukkan bahwa kepemimpinan kepala sekolah mempunyai pengaruh positif dan signifikan terhadap kepuasan kerja guru. Hasil penelitian tersebut linier dengan penelitian dari Gustomo dan Silvianita yang menyatakan bahwa nilai-nilai personal, gaya kepemimpinan dan budaya organisasi memiliki hubungan yang positif dengan kepuasan kerja. (Gustomo dan Silvianita, 2012:1).

Pada hipotesis keenam yakni diduga budaya kerja organisasi berpengaruh secara signifikan terhadap kepuasan kerja guru, hasil penelitian menunjukkan bahwa budaya kerja organisasi mempunyai pengaruh positif dan signifikan terhadap kepuasan kerja guru. Hasil penelitian tersebut linier dengan penelitian dari Suwarto dan Purwoatmodjo yang menyatakan bahwa iklim organisasi mempunyai pengaruh positif terhadap kepuasan kerja. (Suwarto dan Purwoatmodjo, 2011:25).

Pada hipotesis ketujuh yakni diduga motivasi kerja berpengaruh secara signifikan terhadap kepuasan kerja guru, hasil penelitian menunjukkan bahwa motivasi kerja mempunyai pengaruh signifikan terhadap kepuasan kerja guru. Hasil penelitian tersebut linier dengan penelitian dari Bestiana yang menyatakan bahwa kepuasan kerja, motivasi kerja dan komitmen normatif guru sangat berperan untuk meningkatkan kinerja guru bila secara bersama-sama. (Bestiana, 2012:198).

Pada hipotesis kedelapan yakni diduga komunikasi interpersonal dan kepemimpinan kepala sekolah berpengaruh secara simultan dan signifikan terhadap motivasi kerja, hasil penelitian menunjukkan bahwa komunikasi interpersonal dan motivasi kerja mempunyai pengaruh secara simultan dan signifikan terhadap motivasi kerja. Hasil penelitian tersebut linier dengan penelitian dari Kamilin yang menyatakan bahwa budaya organisasi berpengaruh langsung terhadap motivasi kerja guru (Kamilin, 2013:78).

Pada hipotesis kesembilan yakni diduga kepemimpinan kepala sekolah dan budaya kerja organisasi berpengaruh secara simultan dan signifikan terhadap motivasi kerja, hasil penelitian menunjukkan bahwa motivasi kerja dan budaya kerja organisasi tidak mempunyai pengaruh secara simultan dan signifikan terhadap motivasi kerja. Hasil penelitian tersebut tidak linier dengan penelitian dari Kamilin yang menyatakan bahwa budaya organisasi berpengaruh langsung terhadap motivasi kerja guru dan gaya kepemimpinan kepala sekolah berpengaruh secara langsung terhadap motivasi kerja guru (Kamilin, 2013:78). Hasil penelitian penulis tidak linier karena hasil penelitian penulis ini terdapat keterbatasan dalam penelitian dikarenakan instrumen dibuat sendiri oleh peneliti dan responden tidak dikendalikan.

Pada hipotesis kesepuluh yakni diduga komunikasi interpersonal dan budaya kerja organisasi berpengaruh secara simultan dan signifikan terhadap motivasi kerja, hasil 
penelitian menunjukkan bahwa komunikasi interpersonal dan budaya kerja organisasi mempunyai pengaruh secara simultan dan signifikan terhadap motivasi kerja. Hasil penelitian tersebut linier dengan penelitian dari Duta yang menyatakan gaya komunikasi guru dapat mempengaruhi motivasi dan kinerja guru dalam menciptakan suasana yang menyenangkan. (Duta, 2015:1011).

Pada hipotesis kesebelas yakni diduga komunikasi interpersonal, motivasi kerja dan budaya kerja organisasi mempunyai pengaruh secara simultan dan signifikan terhadap motivasi kerja, hasil penelitian menunjukkan bahwa komunikasi interpersonal, motivasi kerja dan budaya kerja organisasi mempunyai pengaruh secara simultan dan signifikan terhadap motivasi kerja. Hasil penelitian tersebut linier dengan penelitian dari Duta yang menyatakan gaya komunikasi guru dapat mempengaruhi motivasi dan kinerja guru dalam menciptakan suasana yang menyenangkan. (Duta, 2015:1011)

\section{PENUTUP}

Komunikasi interpersonal mempunyai pengaruh positif dan signifikan terhadap motivasi kerja dengan hasil uji 4,413 > 1,653. Motivasi kerja mempunyai pengaruh tidak signifikan terhadap motivasi kerja dengan hasil uji $-2,270<1,653$. Budaya kerja organisasi mempunyai pengaruh tidak signifikan terhadap motivasi kerja dengan hasil uji -1,321<1,653. Komunikasi interpersonal mempunyai pengaruh positif tetapi tidak signifikan terhadap kepuasan kerja gurudengan hasil uji 0,506 <1,653. Motivasi kerja mempunyai pengaruh positif dan signifikan terhadap kepuasan kerja gurudengan hasil hasil uji 3,196 > 1,653. Budaya kerja organisasi mempunyai pengaruh positif dan signifikan terhadap kepuasan kerja gurudengan hasil hasil uji 14,601 > 1,653. Motivasi kerja mempunyai pengaruh signifikan terhadap kepuasan kerja guru dengan hasil hasil uji $-1,980>1,653$. Komunikasi interpersonal dan Motivasi kerja mempunyai pengaruh secara simultan dan signifikan terhadap motivasi kerja dengan hasil hasil uji 13,879 > 2,420. Motivasi kerja dan Budaya kerja organisasi tidak mempunyai pengaruh secara simultan dan signifikan terhadap motivasi kerja dengan hasil hasil uji 2,882 $>2,420$. Komunikasi interpersonal dan Budaya kerja organisasi mempunyai pengaruh secara simultan dan signifikan terhadap motivasi kerja dengan hasil hasil uji 11,807 >2,420.

Komunikasi interpersonal, Motivasi kerja dan Budaya kerja organisasi mempunyai pengaruh secara simultan dan signifikan terhadap motivasi kerja dengan hasil hasil uji $9,677>2,420$. Komunikasi interpersonal dan Motivasi kerja mempunyai pengaruh secara simultan dan signifikan terhadap kepuasan kerja gurudengan hasil hasil uji 5,118 > 2,420. Motivasi kerja dan Budaya kerja organisasi mempunyai pengaruh secara simultan dan signifikan terhadap kepuasan kerja guru. Komunikasi interpersonal dan Budaya kerja organisasi mempunyai pengaruh secara simultan dan signifikan terhadap kepuasan kerja guru. Komunikasi interpersonal, Motivasi kerja dan Budaya kerja organisasi mempunyai pengaruh secara simultan dan signifikan terhadap kepuasan kerja guru dengan hasil hasil uji 70,535 > 2,420 .

Komunikasi interpersonal, Motivasi kerja dan Budaya kerja organisasi berpengaruh secara langsung terhadap motivasi kerja dengan nilai signifikansi $<\alpha$ atau $(0,000<0,05)$ dan secara simultan Komunikasi interpersonal, Motivasi kerja dan Budaya kerja organisasi memiliki kontribusi sebesar $14 \%$ dalam menjelaskan perubahan yang terjadi pada variabel motivasi 
kerja dengan pengaruh tidak langsung sebesar $0,44 \%$ dan sisanya dipengaruhi oleh faktor lain di luar model dalam penelitian. Komunikasi interpersonal, Motivasi kerja dan Budaya kerja organisasi berpengaruh secara langsung terhadap kepuasan kerja guru dengan nilai signifikansi $<\alpha$ atau $(0,000<0,05)$ dan secara simultan Komunikasi interpersonal, Motivasi kerja dan Budaya kerja organisasi memiliki kontribusi sebesar 54,3\% dalam menjelaskan perubahan yang terjadi pada variabel kepuasan kerja gurudengan penguaruh tidak langsung sebesar $0,01 \%$ dan sisanya dipengaruhi oleh faktor lain di luar model dalam penelitian.

\section{DAFTAR PUSTAKA}

Nuchiyah, 2007, Pengaruh Kepemimpinan Kepala Sekolah dan Kinerja Mengajar Guru Terhadap Prestasi Belajar Siswa, JURNAL, Pendidikan Dasar “Vol. V - No. 7.

Purwanti, 2013, Peran Kepemimpinan Kepala Sekolah dalam Meningkatkan Disiplin Kerja Guru dan Pegawai di SMA Bakti Sejahtera Kecamatan Kongbeng Kabupaten Kutai Timur, eJournal Administrasi Negara, Volume 1, Nomor 1.

Sunindijo, 2015, Improving Safety Among Small Organisations IN The Construction Industry: Key Barriers and Improvement Strategies, Procedia Engineering 125109 - 116.

Adiwinata, 2014, Pengaruh Kepuasan Kerja dan Motivasi Kerja Terhadap Produktivitas Kerja Karyawan CV. Intaf Lumajang, Agora Vol. 2, No. 1.

Bestiana, 2012, Hubungan Kepuasan Kerja, Motivasi dan Komitmen Normatif Dengan Kinerja Guru SMPN 1 Rantau Selatan - Labuhan Batu, Jurnal Tabularasa PPS Unimed Vol. 9 No. 2.

Rahardja, 2004, Hubungan Antara Komunikasi antar Pribadi Guru dan Motivasi Kerja Guru dengan Kinerja Guru SMUK BPK PENABUR Jakarta, Jurnal Pendidikan Penabur No.03 / Th.III.

Kamaliah, dkk 2011, Pengaruh Gaya Kepemimpinan, Budaya Organisasi dan Motivasi Kerja Terhadap Kinerja Akuntan Pemerintah (Studi Empiris pada Akuntan BPKP), The Journal of Management Development, Vol. 23, No. 4.

Kamilin, 2013, Pengaruh Budaya Organisasi, Gaya Kepemimpinan Kepala Sekolah dan Motivasi Kerja Terhadap Kualitas Profesional Guru SMP Al - Washliyah Kota Medan, Jurnal Tabularasa PPS Unimed Vol.10 No.1.

Cetin et al. 2012, The Effects of Leadership Styles and the Communication Competency of Bank Managers on the Employee's Job Satisfaction: The Case of Turkish Banks, Procedia - Social and Behavioral Sciences 58.

Gustomo dan Silvianita, 2012, Pengaruh Nilai-Nilai Personal, Gaya Kepemimpinan dan Budaya Organisasi terhadap Kepuasan Kerja Karyawan, The Journal of Management Development, Vol. 19, No.2. 